Ambiente \& Água - An Interdisciplinary Journal of Applied Science
ISSN 1980-993X - doi:10.4136/1980-993X
www.ambi-agua.net
E-mail: ambi.agua@gmail.com

\title{
Influência da sazonalidade das vazões nos critérios de outorga de uso da água: estudo de caso da bacia do rio Paraopeba
}

\author{
doi: 10.4136/ambi-agua.1587 \\ Received: 18 Dec. 2014; Accepted: 12 Feb. 2015

\begin{abstract}
Bruno Marcel Barros da Silva ${ }^{1}$; Demetrius David da Silva²; Michel Castro Moreira ${ }^{3 *}$
\end{abstract} \\ ${ }^{1}$ Companhia de Saneamento Ambiental do Distrito Federal (CAESB), Brasília, DF, Brasil \\ ${ }^{2}$ Universidade Federal de Viçosa (UFV), Viçosa, MG, Brasil \\ Departamento de Engenharia Agrícola \\ ${ }^{3}$ Universidade Federal do Oeste da Bahia (UFOB), Barreiras, BA, Brasil \\ Centro das Ciências Exatas e das Tecnologias \\ *Autor correspondente: e-mail: michelcm@ufob.edu.br, \\ bruno_eab@yahoo.com.br, demetrius@ufv.br
}

\section{RESUMO}

O Brasil possui uma das mais modernas leis de gerenciamento de recursos hídricos do mundo. Dentre seus instrumentos de gestão e planejamento, a outorga dos direitos de uso de recursos hídricos permite ao órgão gestor o controle quantitativo e qualitativo dos recursos hídricos. Considerando a importância da outorga como instrumento de controle do uso da água, o objetivo do trabalho foi analisar alternativas de critérios de outorga que considerem a sazonalidade anual das vazões, visando fornecer subsídios técnico-científicos para a tomada de decisão pelos órgãos gestores de recursos hídricos. Os efeitos quantitativos da adoção de períodos sazonais quadrimestrais e semestrais foram analisados em comparação ao período anual das vazões de referência $\mathrm{Q}_{7,10}, \mathrm{Q}_{90}$ e $\mathrm{Q}_{95}$, a fim de se quantificar as diferenças relativas da disponibilidade hídrica entre as vazões de referência adotadas para fins de outorga de uso de água. $\mathrm{Na}$ análise da $\mathrm{Q}_{7,10}$, os resultados mostraram que a aplicação de critérios sazonais pode propiciar aumento de até $126 \%$ na quantidade de água disponível para outorga nos períodos de maior disponibilidade hídrica. Já para as vazões associadas às permanências de 90\% $\left(\mathrm{Q}_{90}\right)$ e $95 \%\left(\mathrm{Q}_{95}\right)$, foram registrados aumentos de até $99 \%$ no período chuvoso, porém, no período seco a redução da disponibilidade hídrica foi de até $24,5 \%$ em comparação com o período anual. Os resultados obtidos permitiram concluir que o uso dos critérios baseados no comportamento hídrico sazonal propicia flexibilização nas vazões outorgáveis em determinados períodos do ano.

Palavras-chave: disponibilidade hídrica, gestão de recursos hídricos, vazão de referência.

\section{Influence of the seasonality of stream flows on water use rights criteria: a case study of the Paraopeba river basin}

\begin{abstract}
Brazil has one of the most modern laws of water resource management in the world. Among its management and planning tools, the granting of water use rights allows water
\end{abstract}


resource management agencies to control water usage both quantitatively and qualitatively. Given the importance of the granting of water use rights as an instrument of water usage control, this paper sought to analyze the criteria used to grant water use rights considering the influence of the seasonality of yearly stream flows, with the objective of establishing a technical, scientific basis for decision-making by water resource management agencies. The quantitative effects of adopting four-month and six-month seasonal period criteria were analyzed in comparison to the annual periods of stream flow references $\mathrm{Q}_{7,10}, \mathrm{Q}_{90}$, and $\mathrm{Q}_{95}$ in order to quantify the relative differences in water availability between the stream flow references adopted for water use rights purposes. In the analysis of $\mathrm{Q}_{7,10}$, the results showed that applying seasonal criteria may increase the amount of water available for water use grants in the periods of higher water availability by up to $126 \%$. Meanwhile, stream flows associated to the permanence of $90 \%\left(\mathrm{Q}_{90}\right)$ and $95 \%\left(\mathrm{Q}_{95}\right)$ showed increases of up to $99 \%$ during the rainy period. During the dry period, however, water availability decreased by up to $24.5 \%$ in comparison with the annual period criteria calculation base period. Results showed that stream flow analysis based on seasonal criteria provides more flexibility of water availability for water use grants during certain periods of the year.

Keywords: reference streamflow, water availability, water resource management.

\section{INTRODUÇÃO}

O gerenciamento integrado dos recursos hídricos é um processo que promove a gestão coordenada do uso da água, solo e recursos relacionados, a fim de maximizar o bem-estar econômico e social resultante de uma forma equitativa, sem comprometer a sustentabilidade dos ecossistemas (GWP, 2000).

Vários países dispõem de arranjos institucionais e administrativos que possibilitam o tratamento adequado da gestão das águas. Do ponto de vista administrativo e institucional, o setor de recursos hídricos já está estruturado para ser tratado de forma individualizada, tal como o setor de transporte, energia e meio ambiente. O Brasil não é exceção, uma vez que dispõe de uma das mais modernas legislações de recursos hídricos, instituída pela Lei $\mathrm{n}^{\circ} 9.433$ de 1997, a chamada Lei das Águas (Braga et al., 2008).

Um dos principais instrumentos de gestão e planejamento de recursos hídricos é a outorga dos direitos de uso de recursos hídricos. A outorga permite ao seu detentor, por um período preestabelecido, o direito de uso de determinada quantidade de água, condicionado a sua disponibilidade, de tal modo que assegure ao órgão gestor o controle quantitativo e qualitativo do seu uso, ao mesmo tempo em que garante ao usuário o direito de uso da água de forma pessoal e intransferível (Moreira, 2006).

As vazões mínimas de referência, adotadas para fins de outorga pelos órgãos gestores de recursos hídricos, influenciam diretamente no total disponível para outorga. Os critérios para análise dos pedidos de outorga utilizados pelos órgãos gestores utilizam diferentes vazões mínimas de referência, bem como percentuais considerados outorgáveis. Segundo Cruz (2001), no Brasil, cada estado, bem como em nível federal, tem-se adotado critérios específicos para o estabelecimento das vazões mínimas de referência para outorga sem, entretanto, apresentar justificativas para a adoção desses valores.

Como apenas parte das vazões mínimas de referência são outorgáveis, há a limitação do uso da água principalmente nos períodos de maior disponibilidade hídrica. A diversidade de vazões mínimas de referência adotadas, assim como de diferentes percentuais desta vazão para outorga, afeta diferentes usuários e suas atividades econômicas, como irrigação, abastecimento urbano, geração de energia, produção industrial, diluição de efluentes, recreação, entre outros. 
$\mathrm{Na}$ bacia do rio Paraopeba, localizada no Estado de Minas Gerais e afluente do rio São Francisco, o Instituto Mineiro de Gestão das Águas (IGAM), responsável pelo gerenciamento dos recursos hídricos, concede a outorga considerando como passível de utilização $30 \%$ da vazão mínima com sete dias de duração e período de retorno de 10 anos $\left(\mathrm{Q}_{7,10}\right)$.

Ao se utilizar no processo de outorga um valor fixo de $\mathrm{Q}_{7,10} \mathrm{em}$ todos os meses do ano, desconsidera-se as variações sazonais da disponibilidade hídrica, implicando na concessão de vazões bastante restritivas em períodos de maior disponibilidade (Bof et al., 2013; Euclydes et al., 2006).

A restrição do critério de outorga adotado no Estado de Minas Gerais requer a discussão e a definição de diferentes critérios de outorga, conforme as particularidades de cada região. Este procedimento poderia minimizar os conflitos pelo uso da água já evidenciados em diferentes bacias do Estado, motivo pelo qual o presente trabalho teve por objetivo analisar a influência da sazonalidade das vazões da bacia do rio Paraopeba nos critérios de outorga de uso da água, visando fornecer subsídios técnico-científicos para a tomada de decisão pelos órgãos gestores de recursos hídricos.

\section{MATERIAL E MÉTODOS}

\section{1. Área de estudo}

A bacia do rio Paraopeba (Figura 1), situada no Alto São Francisco, abrange uma área de drenagem de $13.642 \mathrm{~km}^{2}$, representando 2,3\% da área do Estado de Minas Gerais e contribuindo com cerca de $9,1 \%$ do volume médio escoado na foz do rio São Francisco (Pereira, 2004).

O rio Paraopeba possui $510 \mathrm{~km}$ de comprimento e é um dos mais importantes tributários do rio São Francisco (Alves, 2007). Seus principais afluentes na margem direita são os rios Maranhão e Betim e o ribeirão São João, e os da margem esquerda são os rios Camapuã, Manso e Pardo e os ribeirões Serra Azul e Florestal (Naghettini e Viviane, 2010). Sua nascente situa-se no sul do município de Cristiano Ottoni e sua foz no lago de Três Marias, no município de Felixlândia (Silva Júnior et al., 2003).

A região mais densamente povoada se encontra no terço central da bacia, onde se situa um dos mais importantes centros econômicos de Minas Gerais, localizado entre Contagem e Betim, formando o segundo polo industrial automobilístico do país. Juntos estes dois municípios respondem por aproximadamente $12,5 \%$ do PIB de Minas Gerais. No setor minerário, a bacia merece destaque, por fornecer agregados finos para construção civil, pedras ornamentais e minério de ferro (CIBAPAR, 2009).

\subsection{Vazões mínimas de referência}

\subsubsection{Base de dados}

A fim de estimar as vazões mínimas de referência comumente utilizadas como critério de outorga pelos órgãos gestores de recursos hídricos do país, no presente estudo foram consideradas as vazões mínimas com sete dias de duração e período de retorno de 10 anos $\left(\mathrm{Q}_{7,10}\right)$, e as vazões mínimas associadas às permanências de $90 \%\left(\mathrm{Q}_{90}\right)$ e $95 \%\left(\mathrm{Q}_{95}\right)$. Para o cálculo das vazões mínimas de referência, foram analisados os dados consistidos de 13 estações fluviométricas da bacia do rio Paraopeba (Tabela 1), pertencentes à rede hidrometeorológica da Agência Nacional de Águas (ANA), disponibilizados no Sistema de Informações Hidrológicas (HidroWeb).

A partir do banco de dados das estações fluviométricas, foram elaborados diagramas de barras para cada estação com a finalidade de se observar possíveis falhas nos dados. Esta análise preliminar permitiu a escolha do período-base (período comum de dados) de 23 anos, 
compreendendo os anos de 1983 a 2005. Os dados mais recentes, referente ao período posterior a 2006, não foram utilizados por não estarem consistidos no sistema HidroWeb.
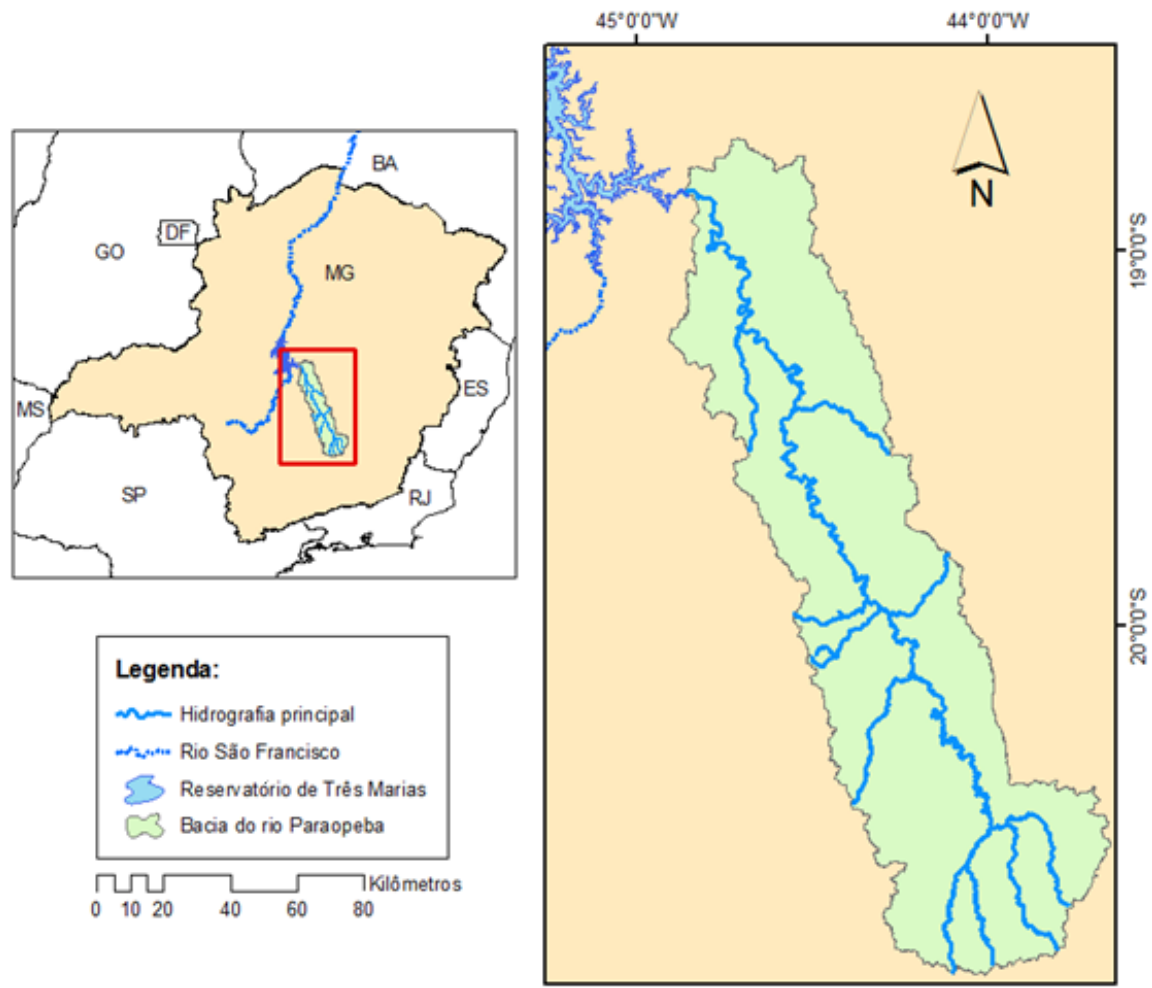

Figura 1. Localização da bacia do rio Paraopeba.

Tabela 1. Estações fluviométricas da bacia do rio Paraopeba utilizadas no estudo.

\begin{tabular}{|c|c|c|c|c|c|}
\hline Código & Nome & $\begin{array}{l}\text { Latitude } \\
\text { (Sul) }\end{array}$ & $\begin{array}{l}\text { Longitude } \\
\text { (Oeste) }\end{array}$ & $\begin{array}{c}\text { Área de } \\
\text { drenagem } \\
\left(\mathrm{km}^{2}\right)\end{array}$ & Curso d'água \\
\hline 40549998 & São Brás do Suaçui - Montante & $20^{\circ} 36^{\prime} 14^{\prime \prime}$ & $43^{\circ} 54^{\prime} 31^{\prime \prime}$ & 446 & Rio Paraopeba \\
\hline 40579995 & Congonhas - Linígrafo & $20^{\circ} 31^{\prime} 07^{\prime \prime}$ & $43^{\circ} 50^{\prime} 08^{\prime \prime}$ & 613 & Rio Maranhão \\
\hline 40680000 & Entre Rios de Minas & $20^{\circ} 39^{\prime} 37^{\prime \prime}$ & $44^{\circ} 04^{\prime} 19^{\prime \prime}$ & 469 & Rio Brumado \\
\hline 40710000 & Belo Vale & $20^{\circ} 24^{\prime} 29^{\prime \prime}$ & $44^{\circ} 011^{\prime} 16^{\prime \prime}$ & 2.690 & Rio Paraopeba \\
\hline 40740000 & Alberto Flores & $20^{\circ} 09^{\prime} 25^{\prime \prime}$ & $44^{\circ} 10^{\prime} 00^{\prime \prime}$ & 3.945 & Rio Paraopeba \\
\hline 40800001 & Ponte Nova do Paraopeba & $19^{\circ} 56^{\prime} 56^{\prime}$, & $44^{\circ} 18^{\prime} 19^{\prime \prime}$ & 5.680 & Rio Paraopeba \\
\hline 40810350 & Fazenda Laranjeiras & $20^{\circ} 05^{\prime} 39^{\prime \prime}$ & $44^{\circ} 29^{\prime} 37^{\prime \prime}$ & 10 & Córrego Mato Frio \\
\hline 40810800 & Fazenda Pasto Grande & $20^{\circ} 03^{\prime} 38^{\prime \prime}$ & $44^{\circ} 27^{\prime} 08^{\prime \prime}$ & 55 & Ribeirão Serra Azul \\
\hline 40811100 & Jardim & $20^{\circ} 02^{\prime} 51^{\prime \prime}$ & $44^{\circ} 24^{\prime} 32^{\prime \prime}$ & 112 & Ribeirão Serra Azul \\
\hline 40821998 & Bom Jardim & $19^{\circ} 59^{\prime} 43^{\prime \prime}$ & $44^{\circ} 31^{\prime} 50^{\prime \prime}$ & 40 & Ribeirão Sesmaria \\
\hline 40822995 & Mateus Leme - Aldeia & $19^{\circ} 58^{\prime} 10^{\prime \prime}$ & $44^{\circ} 25^{\prime} 19^{\prime \prime}$ & 90 & Ribeirão Mateus Leme \\
\hline 40823500 & Suzana & $19^{\circ} 57^{\prime} 41^{\prime \prime}$ & $44^{\circ} 21^{\prime} 58^{\prime \prime}$ & 153 & Ribeirão Mateus Leme \\
\hline 40850000 & Ponte da Taquara & $19^{\circ} 25^{\prime} 23^{\prime}$, & $44^{\circ} 32^{\prime} 52^{\prime \prime}$ & 8.720 & Rio Paraopeba \\
\hline
\end{tabular}

\subsubsection{Identificação dos períodos sazonais}

A partir dos dados das estações fluviométricas da bacia, o ano hidrológico foi determinado com a finalidade de servir de base temporal de avaliação em substituição ao ano civil. A determinação do ano hidrológico foi executada com base na observação da variabilidade do comportamento hidrológico da bacia, conforme realizado por Marques (2010). 
Visando a flexibilidade anual dos critérios de outorga em consonância com a variabilidade natural do regime hidrológico, a definição dos intervalos de tempo utilizados no estudo de flexibilidade sazonal dos critérios de outorga baseou-se no agrupamento dos meses em quadrimestres (seco, normal e chuvoso) e semestres (seco e chuvoso) que possuem o regime de hidrológico homogêneo.

No agrupamento dos meses em quadrimestres, foram estabelecidas três tendências de disponibilidade hídrica ao longo do ano: mínima, média e máxima. Na tendência de mínima, ou quadrimestre seco, devido à estiagem, as vazões observadas estão próximas da vazão mínima anual. Na tendência média, ou quadrimestre normal, as vazões aproximam-se das vazões médias anuais e a ocorrência de eventos mínimos são menos frequentes. A tendência de máxima é consequência do quadrimestre chuvoso, que implica poucos ou nenhum evento de vazão mínima registrado.

No agrupamento dos meses em semestres, foram estabelecidas duas tendências de disponibilidade hídrica, sendo elas a seca e a chuvosa. Para tal, foram agrupados seis meses consecutivos, em um período de 12 meses de análise, com menores valores de vazões mínimas para constituir o semestre seco, enquanto os demais seis meses constituíram o semestre chuvoso.

\subsubsection{Estimativa das vazões mínimas de referência}

A fim de avaliar a flexibilidade permitida aos critérios de outorga e, ainda, visando subsidiar as políticas de gestão dos recursos hídricos, além do tradicional período anual utilizado pelos órgãos gestores, os períodos sazonais foram utilizados na determinação das vazões mínimas de referência $\left(\mathrm{Q}_{7,10}, \mathrm{Q}_{90}\right.$ e $\left.\mathrm{Q}_{95}\right)$.

No cálculo da $\mathrm{Q}_{7,10}$, foi inicialmente calculado para cada estação o valor da vazão $\mathrm{Q}_{7}$ para cada ano, o qual corresponde a menor média dos valores de vazão de sete dias consecutivos. Como a vazão mínima $\mathrm{Q}_{7,10}$ está associada a um determinado nível de risco, ou seja, associada a um período de retorno específico $\left(\mathrm{T}=10\right.$ anos), as séries anuais de $\mathrm{Q}_{7}$ para cada período de referência utilizado foram submetidas à análise estatística para identificação do modelo probabilístico que melhor se ajustava aos dados.

Os modelos probabilísticos avaliados para as vazões mínimas foram os seguintes: Log-Normal a dois e três parâmetros, Pearson III, Log-Pearson III e Weibull. A seleção da distribuição de probabilidade que melhor se ajustou a cada uma das séries anuais de $\mathrm{Q}_{7}$ foi realizada com base na amplitude do intervalo de confiança com 95\% de probabilidade e no erro padrão.

Os valores de $\mathrm{Q}_{90}$ e $\mathrm{Q}_{95}$ foram obtidos a partir das curvas de permanência de cada estação fluviométrica, com base em dados diários, retratando a parcela de tempo que determinada vazão é igualada ou superada durante o período analisado. Para tanto, as séries de dados de vazões foram organizadas em ordem decrescente e determinou-se a frequência associada a cada valor de vazão.

Para a estimativa das vazões mínimas de referência $\left(\mathrm{Q}_{7,10}, \mathrm{Q}_{95}\right.$ e $\left.\mathrm{Q}_{90}\right)$ em todas as escalas temporais (quadrimestral, semestral e anual) foi utilizado o Sistema Computacional para Análises Hidrológicas (SisCAH 1.0). Este programa computacional foi desenvolvido pela Universidade Federal de Viçosa, e possui uma série de módulos computacionais que permitem realizar diversas análises do comportamento hidrológico em seções específicas da hidrografia.

\subsection{Comparação entre as vazões mínimas de referência de base sazonal e anual}

A partir das estimativas das vazões mínimas de referência foram comparadas as vazões dos períodos quadrimestral e semestral com as do período anual. Nessa comparação foi verificada a diferença relativa da disponibilidade hídrica na vazão disponível para outorga, 
considerando a adoção das vazões mínimas de referência dos períodos quadrimestrais e semestrais com o período anual, conforme a Equação 1:

$$
\mathrm{D}_{\mathrm{p}}=\frac{\mathrm{Q}_{\text {sazonal }}-\mathrm{Q}_{\text {anual }}}{\mathrm{Q}_{\text {anual }}} \times 100
$$

em que:

$\mathrm{D}_{\mathrm{p}}=$ diferença relativa percentual da disponibilidade hídrica, \%;

$\mathrm{Q}_{\text {sazonal }}$ vazão estimada em base sazonal, $\mathrm{m}^{3} \mathrm{~s}^{-1}$, e

$Q_{\text {anual }}$ vazão estimada em base anual, $\mathrm{m}^{3} \mathrm{~s}^{-1}$.

Para visualização dos resultados foram elaborados gráficos, em escala comparativa, da diferença percentual da disponibilidade hídrica resultante da substituição da escala temporal anual por quadrimestral ou semestral.

\section{RESULTADOS E DISCUSSÃO}

\subsection{Períodos sazonais}

Na Figura 2 apresenta-se a divisão sazonal do regime hidrológico da bacia do rio Paraopeba considerando a média da vazão específica mínima ( $\mathrm{q}_{\mathrm{esp}}$ mínima) das estações fluviométricas utilizadas no estudo. A partir da análise da média das vazões específicas mínimas, foram agrupados os quadrimestres com menores valores de médias mínima, configurando assim o período de tendência de vazões mínimas, ou seja, o quadrimestre seco. Deste modo, obteve-se a divisão do ano civil nos quadrimestres $\operatorname{seco}\left(\mathrm{Q}_{\mathrm{se}}\right)$, normal $\left(\mathrm{Q}_{\mathrm{no}}\right)$ e chuvoso $\left(\mathrm{Q}_{\mathrm{ch}}\right)$.

O quadrimestre normal apresentou o movimento da vazão mínima no sentido decrescente rumo ao quadrimestre seco, conforme observado por Marques (2010), enquanto o quadrimestre chuvoso apresenta os meses em que se verifica o movimento de aumento das vazões mínimas como resultado do início das chuvas.

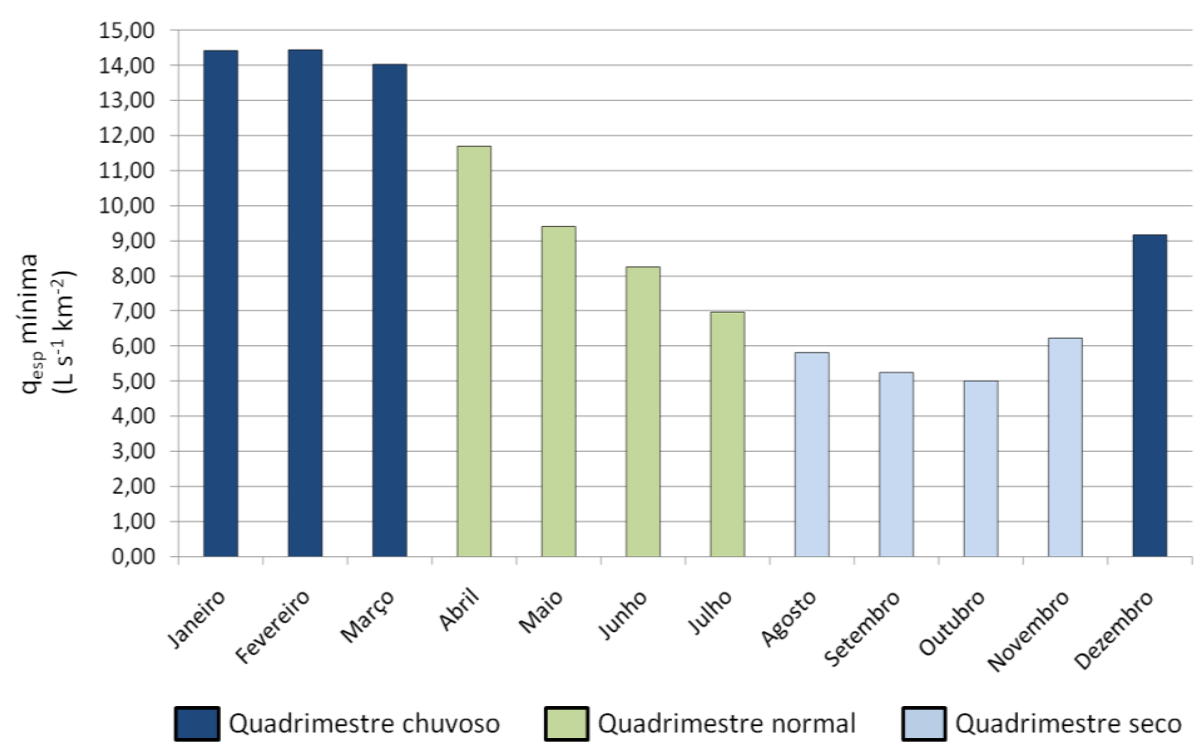

Figura 2. Divisão sazonal do regime hidrológico da bacia do rio Paraopeba considerando a média da vazão específica mínima ( $\mathrm{q}_{\text {esp }}$ mínima) das estações fluviométricas utilizadas no estudo. 
Seguindo os mesmos critérios de comportamento hidrológico e a análise dos valores das vazões específicas mínima, foi possível determinar os semestres seco $\left(\mathrm{S}_{\mathrm{se}}\right)$ e chuvoso $\left(\mathrm{S}_{\mathrm{ch}}\right)$. $\mathrm{O}$ semestre seco tem início no mês de junho, que possui menor valor de média mínima que maio e finaliza no mês de novembro, que possui valor de média mínima inferior ao mês de dezembro. O semestre chuvoso inicia-se no mês de dezembro e finaliza no mês de maio.

Apesar de se verificar o aumento pluviométrico na região no mês de outubro, os eventos chuvosos não são constantes e não apresentam magnitudes elevadas o suficiente para garantir um aumento das vazões mínimas que continuam a registrar eventos menores ao longo dos meses de outubro e novembro. Isto pode ser justificado pelo conceito de inércia hídrica (Novaes et al., 2009), que corresponde à precipitação mínima necessária para garantir a recarga do aquífero freático e, assim, garantir escoamento no leito do rio advindo da contribuição subterrânea.

A Figura 3 apresenta a frequência de ocorrências de $\mathrm{Q}_{7}$ ao longo do ano e sua porcentagem relacionada aos quadrimestres (Figura 3a) e semestres (Figura 3b). Pela análise da Figura $3 a$ observa-se que a frequência de ocorrência dos valores de $\mathrm{Q}_{7}$ anual corrobora a classificação dos meses nas tendências propostas. O quadrimestre seco concentra $75,25 \%$ das ocorrências de $\mathrm{Q}_{7}$ anual, ou seja, em média há $75,25 \%$ de risco para a ocorrência dos sete dias mais secos do ano nos meses de agosto a novembro. Nos meses do quadrimestre normal, de abril a julho, este risco é de aproximadamente $13,94 \%$, enquanto no quadrimestre chuvoso ainda há risco de aproximadamente $10,91 \%$ de ocorrência de um evento de $\mathrm{Q}_{7}$.

Pode-se ainda verificar pela análise da Figura 3 a que no mês de novembro o risco de ocorrência de um evento de $\mathrm{Q}_{7}$ é $9,09 \%$, valor $150 \%$ maior do que o risco de ocorrência no mês de julho e $36 \%$ maior que no mês de dezembro.

A Figura $3 b$ apresenta a análise de frequência para os semestres seco e chuvoso. Nota-se que a frequência de ocorrência de eventos de $\mathrm{Q}_{7}$ no semestre chuvoso e seco é de aproximadamente $16 \%$ e $84 \%$, respectivamente. A probabilidade de ocorrência deste evento no mês de dezembro é superior ao mês de abril, no entanto, devido às características pluviométricas da região e os valores das vazões específicas mínimas o mês de dezembro é caracterizado como chuvoso.

\subsection{Comparação entre as vazões mínimas de referência de base sazonal e anual}

$\mathrm{Na}$ Tabela 2 apresenta-se a diferença percentual média das vazões sazonais em relação à vazão anual correspondente às estações fluviométricas utilizadas no estudo. Verifica-se, pela análise dos valores da Tabela 2, que houve flexibilidade do uso das vazões com a adoção dos períodos sazonais.

$\mathrm{Na}$ análise da $\mathrm{Q}_{7,10}$, verifica-se que os quadrimestres chuvoso e normal e o semestre chuvoso apresentaram flexibilidade média de $126 \%, 72 \%$ e $96 \%$, respectivamente. Não houve flexibilização das vazões no quadrimestre seco e semestre seco, uma vez que, em poucos casos, as ocorrências de $\mathrm{Q}_{7}$ anual ocorreram fora deste período. Deste modo, a $\mathrm{Q}_{7,10}$ em base anual possui valor correspondente aos valores de $\mathrm{Q}_{7,10}$ dos quadrimestre seco e semestre seco.

Em relação às vazões mínimas associadas à curva de permanência, foi observada flexibilidade nos quadrimestres normal e chuvoso, assim como no semestre chuvoso. No quadrimestre seco e semestre seco não houve flexibilização, ou seja, houve diminuição dos valores das vazões de referência no quadrimestre seco (-24,5\% para a $\mathrm{Q}_{90}$ e $-22,7 \%$ para a $\mathrm{Q}_{95}$ ) e semestre seco (-18\% para a $\mathrm{Q}_{90}$ e $-17,5 \%$ para a $\mathrm{Q}_{95}$ ). Este comportamento era esperado, conforme foi também evidenciado por Bof (2010) e Marques et al. (2009). 
(a)

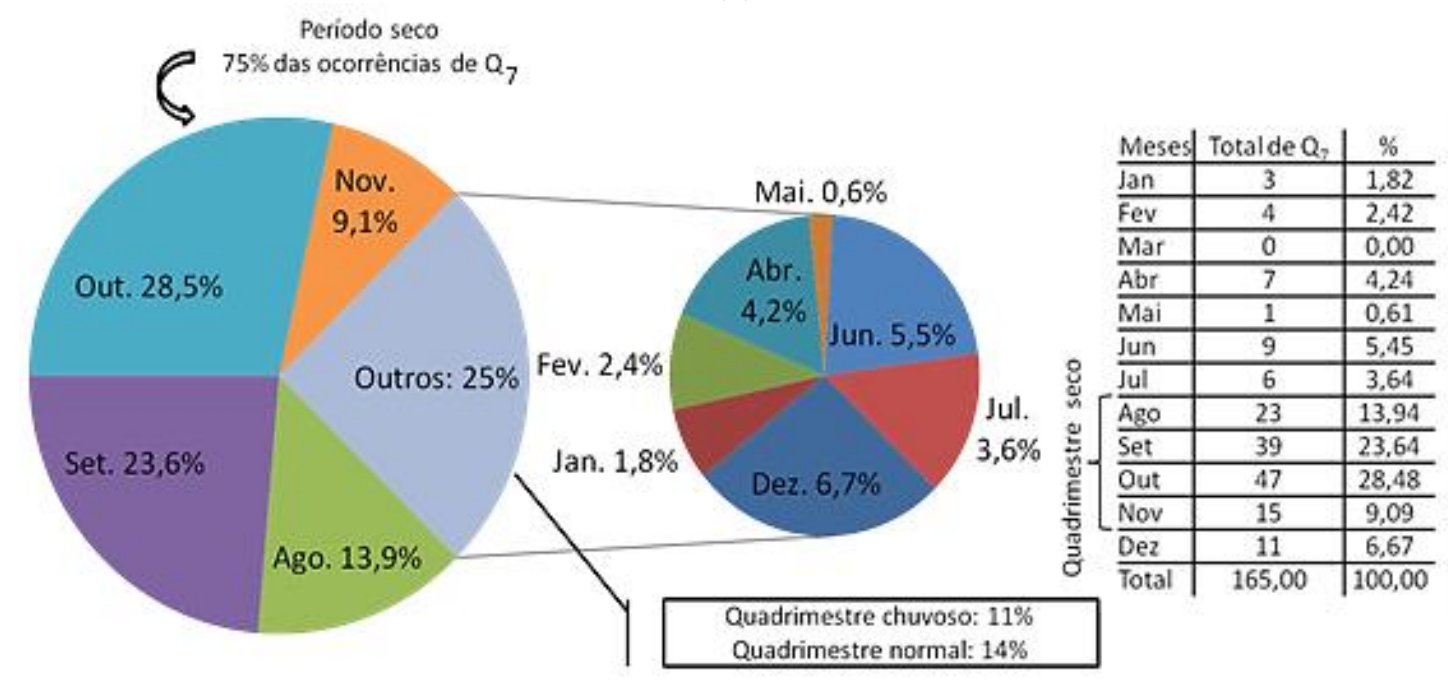

(b)
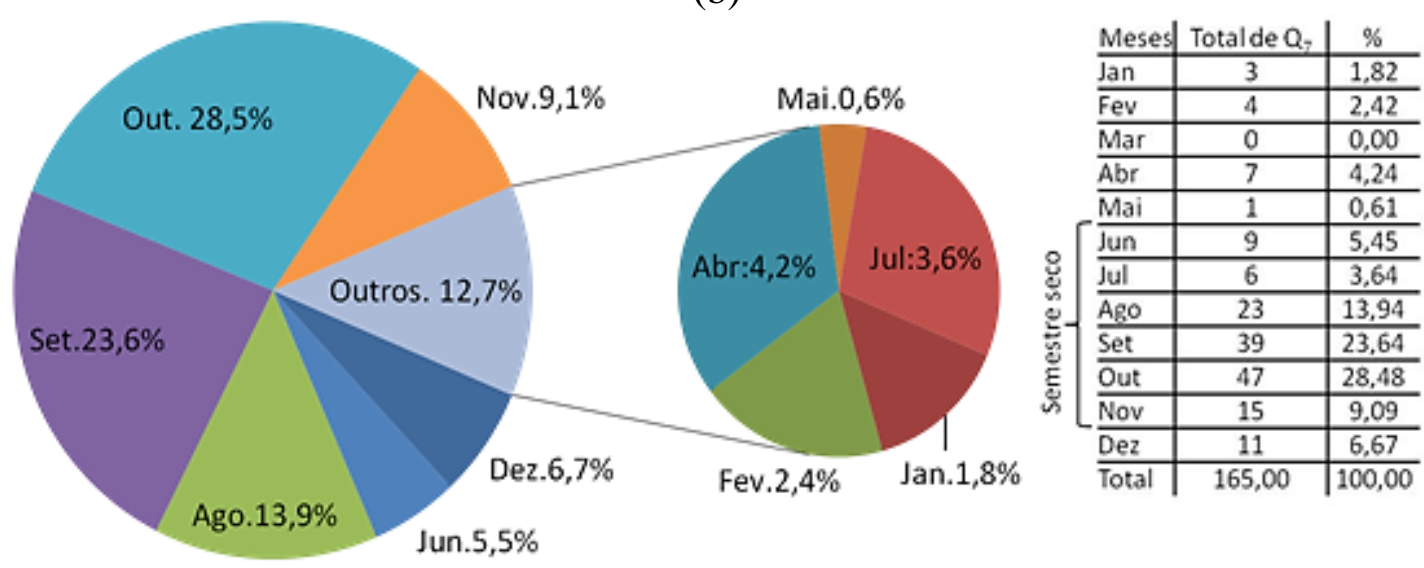

Figura 3. Frequência de ocorrências de $\mathrm{Q}_{7}$ ao longo do ano e sua porcentagem relacionada aos: a) quadrimestres; e b) semestres.

Tabela 2. Diferença percentual média das vazões sazonais em relação à vazão anual correspondente às estações fluviométricas utilizadas no estudo.

\begin{tabular}{ccccccc}
\hline \multirow{2}{*}{$\begin{array}{c}\text { Vazões de } \\
\text { referência }\end{array}$} & \multicolumn{3}{c}{ Quadrimestre } & & \multicolumn{2}{c}{ Semestre } \\
\cline { 2 - 3 } \cline { 6 - 7 } & Chuvoso & Normal & Seco & & Chuvoso & Seco \\
\hline $\mathrm{Q}_{7,10}$ & 126,3 & 72,3 & 0,5 & & 95,8 & $-0,4$ \\
$\mathrm{Q}_{90}$ & 99,0 & 17,1 & $-24,5$ & & 68,6 & $-18,0$ \\
$\mathrm{Q}_{95}$ & 97,1 & 22,6 & $-22,7$ & & 75,0 & $-17,5$ \\
\hline
\end{tabular}

Na Figura 4 apresentam-se as diferenças percentuais nos períodos sazonais estudados para as estações fluviométricas utilizadas no estudo, considerando os quadrimestres chuvoso 
(Figura 4a); normal (Figura 4b); seco (Figura 4c); e os semestres chuvoso (Figura 4d) e seco (Figura 4e).

(a)

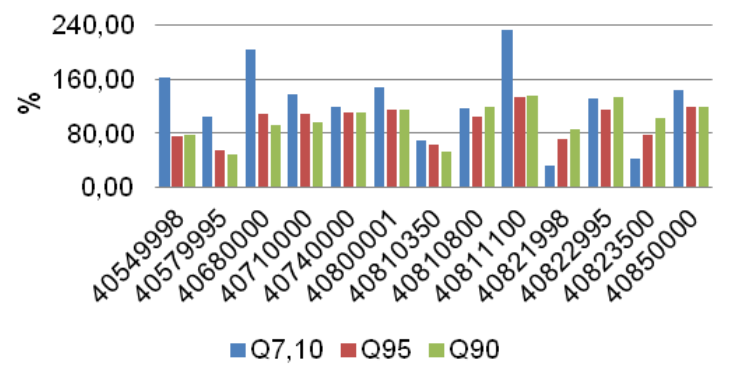

(b)

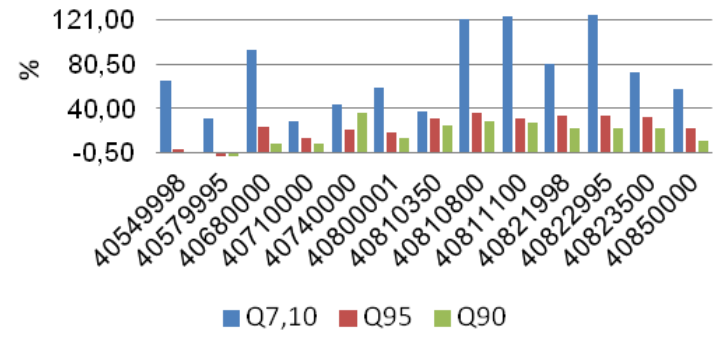

(c)

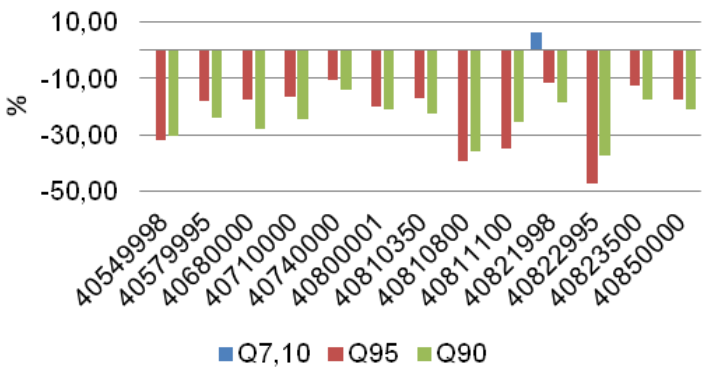

(d)

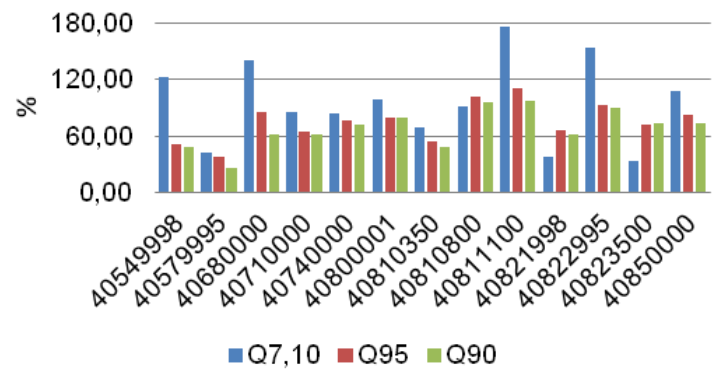

Figura 4. Diferenças percentuais nos períodos sazonais estudados para as estações fluviométricas utilizadas no estudo: a) quadrimestre chuvoso; b) quadrimestre normal; c) quadrimestre seco; d) semestre chuvoso; e) semestre seco.

As estações com valores de $\mathrm{Q}_{7}$ fora do quadrimestre seco e semestre seco tiveram vazões maiores que as vazões de base anual e, portanto, apresentaram flexibilidade em relação ao quadrimestre seco, conforme se verifica nas Figuras 4c e 4e. Nesta condição, estão as estações Bom Jardim (40821998), que apresentou flexibilidade no quadrimestre e semestre seco, e Belo Vale (40710000), que apresentou flexibilidade no semestre seco.

$\mathrm{Na}$ análise das vazões de referência $\mathrm{Q}_{90}$ e $\mathrm{Q}_{95}$, ao se considerar os quadrimestres chuvoso e normal e o semestre chuvoso, os valores da $Q_{90}$ e $Q_{95}$ sazonais foram superiores quando comparados ao período anual de dados.

Este fato se explica pela alteração do comportamento da curva de permanência devido à diminuição do período de análise e a utilização dos dados de vazão dos períodos de maior disponibilidade hídrica, acarretando no achatamento do gráfico, conforme se verifica na Figura 5.

As estações Fazenda Pasto Grande (40810800), Bom Jardim (40821998) e Suzana (40823500) apresentaram vazão maior no período normal quando comparado ao quadrimestre chuvoso, acarretando, assim, maior flexibilidade nesse quadrimestre. 


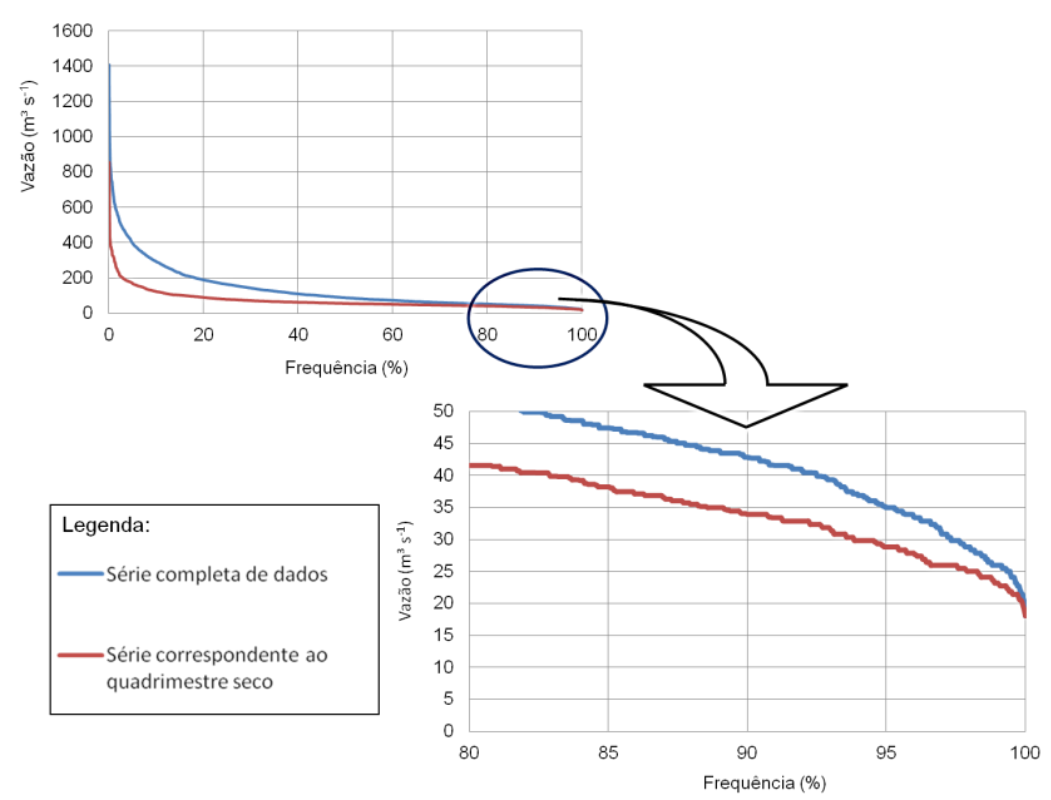

Figura 5. Achatamento da curva de permanência da estação Ponte de Taquara (40850000) de acordo com as séries de vazão do período anual e do quadrimestre seco.

Conforme observado pelas análises das Figuras 4 e 5, a aplicação de períodos sazonais para aumento da flexibilidade na disponibilidade hídrica para outorga corrobora os resultados de diversos autores (Bof et al., 2013; Catalunha, 2004; Euclydes et al., 2006; Marques, 2010; Silva et al., 2011) sendo que, apesar das singularidades quanto ao tipo de período sazonal escolhido, estes relataram ganhos percentuais no uso da vazão sazonal nos períodos de maior disponibilidade comparativamente à vazão anual correspondente.

A análise quantitativa sazonal da disponibilidade hídrica permite elevar a possibilidade de exploração da água. No entanto, a fim de garantir os usos múltiplos da água de forma racional, é necessário contemplar a análise qualitativa da água, pois, certas características em empreendimentos fazem com que suas atividades se deem também de forma sazonal, quando haverá então maior consumo e aporte de efluentes despejados no corpo receptor, mesmo que este fato não coincida com o período de maior escassez de água na bacia.

\section{CONCLUSÕES}

A análise dos resultados obtidos permitiram concluir que:

- As diferenças relativas entre as vazões mínimas de referência sazonais e as de base anual foram expressivas nos quadrimestres normal e chuvoso e no semestre chuvoso;

- Não houve diferença relativa da $\mathrm{Q}_{7,10}$ no semestre e quadrimestre secos em relação a base anual, enquanto que as vazões $\mathrm{Q}_{90}$ e $\mathrm{Q}_{95}$ nestes dois períodos sazonais foram menores comparativamente ao período anual; e

- O uso dos critérios baseados no comportamento hídrico sazonal propiciou flexibilização nas vazões outorgáveis na bacia do rio Paraopeba nos quadrimestres chuvoso e normal assim como no semestre chuvoso.

\section{AGRADECIMENTOS}

À Fundação de Amparo à Pesquisa do Estado de Minas Gerais - FAPEMIG (Processo $\mathrm{n}^{\circ}$ 00220/09) e ao Conselho Nacional de Desenvolvimento Científico e Tecnológico - CNPq (Processo n ${ }^{\circ}$ 302288/2008-2), pelo apoio financeiro. 


\section{REFERÊNCIAS}

ALVES, C. B. M. Evaluation of fish passage through the Igarapé Dam fish ladder (rio Paraopeba, Brazil), using marking and recapture. Neotropicaç Ichthyology v. 5, n. 2, p. 233-236. 2007. http://dx.doi.org/10.1590/S1679-62252007000200019

BRAGA, B. P. F.; FLECHA, R.; PENA, D. S.; KELMAN, J. Pacto federativo e gestão de águas. Estudos Avançados, v. 22, n. 63, p. 17-42. 2008.

http://dx.doi.org/10.1590/S0103-40142008000200003

BOF, L. H. N. Análise de critérios de outorga de direito de uso de recursos hídricos. 2010. 99 f. Dissertação (Mestrado em Engenharia Agrícola) - Universidade Federal de Viçosa, Viçosa, MG, 2010.

BOF, L. H. N.; PRUSKI, F. F.; SILVA, L. M C. da; JUSTINO, F. Analysis of appropriate timescales for water diversion permits in Brazil. Environmental Management, v. 51, p. 492-500, 2013. http://dx.doi.org/10.1007/s00267-012-9982-7

CATALUNHA, M. J. Sistema integrado em rede para gestão do uso múltiplo da água e regionalização da $\mathbf{Q}_{7,10}$ para os períodos mensal, bimestral, trimestral e anual. 2004. 165 f. Tese (Doutorado em Engenharia Agrícola) - Universidade Federal de Viçosa, Viçosa, MG, 2004.

CONSÓRCIO INTERMUNICIPAL DA BACIA HIDROGRÁFICA DO RIO PARAOPEBA - CIBAPAR. Plano diretor da bacia do Rio Paraopeba - resumo preliminar. Betim: IGAM; UFV; UFOP; CETEC, 2009. 83 p.

CRUZ, J. C. Disponibilidade hídrica para outorga: avaliação de aspectos técnicos e conceituais. 2001. 189 f. Tese (Doutorado em Engenharia) - Universidade Federal do Rio Grande do Sul, Porto Alegre, 2001.

EUCLYDES, H. P.; FERREIRA, P. A.; FARIA FILHO, R. F. Critério de outorga sazonal para a agricultura irrigada no estado de Minas Gerais - Estudo de Caso. Revista Item Irrigação e Tecnologia Moderna. Brasília, n. 71/72, p. 42-50, 2006.

GLOBAL WATER PARTNERSHIP - GWP. Integrated water resources management. Stockholm: Technical Advisory Committee, 2000.

MARQUES, F. A. Sistema de controle dinâmico para a gestão dos usos múltiplos da água. 2010. $234 \mathrm{f}$. Tese (Doutorado em Engenharia Agrícola) - Universidade Federal de Viçosa, Viçosa, MG, 2010.

MARQUES, F. A.; SILVA, D. D.; RAMOS, M. M.; PRUSKI, F. F. Estimativas de vazões mínimas mediante dados pluviométricos na bacia hidrográfica do Ribeirão Santa Bárbara, Goiás. Revista Brasileira de Recursos Hídricos. v. 14, n. 4, p. 51-69, 2009.

MOREIRA, M. C. Gestão de recursos hídricos: sistema integrado para otimização da outorga de uso da água. 2006. 97 f. Dissertação (Mestrado em Engenharia Agrícola) Universidade Federal de Viçosa, Viçosa, MG, 2006.

NAGHETTINI, M.; VIVIANE, B. P. Calibração e um modelo chuva-vazão em bacias sem monitoramento fluviométrico a partir de curvas de permanência sintéticas. Revista Brasileira de Recursos Hídricos, v. 15, n. 2, p. 143-156, 2010. 
NOVAES, L. F.; PRUSKI, F. F.; PEREIRA, S. B.; QUEIROZ, D. O.; RODRIGUEZ, R. del G.; SILVA, D. D. da. Gestão de recursos hídricos: uma nova metodologia para estimativa das vazões mínimas. Engenharia na Agricultura, v. 17, p. 35-45, 2009.

PEREIRA, S. B. Evaporação no lago de sobradinho e disponibilidade hídrica no rio São Francisco. 2004. 103 f. Tese (Doutorado em Engenharia Agrícola) - Universidade Federal de Viçosa, Viçosa, MG, 2004.

SILVA, D. D.; MARQUES, F. A.; LEMOS, A. F. Flexibilidade das Vazões Mínimas de Referência com a Adoção do Período Trimestral. Engenharia na Agricultura, v. 19, n. 3, 2011.

SILVA JÚNIOR, O. B.; BUENO, E. O.; TUCCI, C. E. M.; CASTRO, N. M. R. Extrapolação espacial na regionalização da vazão. Revista Brasileira de Recursos Hídricos, v. 8, n. 1, p. 21-37, 2003. 